\title{
The Coevolution of Routines and IT Systems in IT-enabled Organizational Transformation as an Instance of Digital Transformation: A Social Constructivist Perspective
}

\section{Faqir Taj}

School of Accounting, Information Systems and Supply Chains

College of Business, RMIT University

\section{Karlheinz Kautz}

School of Accounting, Information Systems and Supply Chains

College of Business, RMIT University

karlheinz.kautz@rmit.edu.au

\section{Vince Bruno}

School of Accounting, Information Systems and Supply Chains College of Business, RMIT University

\section{Abstract}

This paper proposes a conceptual framework to study the phenomenon of IT-enabled Organizational Transformation (IT-enabled OT) as a coevolution process of organizational routines and a new IT system. The framework's objective is to understand IT-enabled OT in a holistic and integrated manner by investigating how actors perceive, interpret, appropriate, and enact, the new IT system in their work routines as well as how they align the new system and these routines with the social order and structures of the organization. It allows the examination of the reciprocal interactions between different aspects of organizational routines and a new IT system to enhance the understanding of how change unfolds in an organization during the implementation, the adoption, use, and adaptation of a new IT system. We illustrate the scope, the analytic and conceptual strength of the framework with a number of examples from the literature and, lastly, discuss its ontological positioning. The paper concludes with a call for further research to empirically validate and refine the proposed framework.

Keywords: IT-enabled OT, organizational routines, coevolution, appropriation, enactment

\section{Introduction}

Digital Transformation (DT) has emerged as an important phenomenon in IS research and practice. In a recent comprehensive literature review Vial (2019) defines DT as "a process that aims to improve an entity by triggering significant changes to its properties through combinations of information, computing, communication, and connectivity technologies" where the concept entity refers to either an organization, an industry or society (Vial, 2019, p. 121).

Both Agarwal et al. (2010) and Vial (2019) discuss, that at a high level, DT encompasses the profound changes taking place in society and industry through the use of digital technologies. Additional grounding in the extant literature (e.g. Hess et al., 2016) Vial (2019) states that at the organizational level DT refers to the reaction of contemporary firms to find ways to innovate with these technologies by devising and implementing strategies to drive better operational performance and to remain competitive in a digital world. In this context he refers to previous research and the concept of IT-enabled organizational transformation. While 
Wessel et al. (2020) posit that DT leverages digital technology by (re)defining an organization's value proposition and involves a new organizational identity whereas IT-enabled OT leverages digital technology in supporting the existing value proposition and enhances an existing organizational identity, the authors also state that the two might overlap and that DT could comprise IT-enabled OT. We therefore consider IT-enabled OT as an instance of DT because it has a particular focus on organizational change as a necessary step to unlock the transformative potential of digital technologies in an organization (Vial, 2019).

The concept of IT-enabled OT encompasses the substantial changes that occur to the structure and work practices of an organization due to the implementation comprising the adoption, use, and adaptation of a new IT system (Weick, 1993; Orlikowski, 1996; Leonardi \& Barley, 2010; Besson \& Rowe, 2012). Orlikowski (1996) presented a study of a customer support system where the structure and organizing practices of a software company were radically changed over a period of two years following the introduction of a new IT system. For instance, the nature of work in the organization changed from unstructured to more structured, patterns of interactions changed from reactive to proactive, and coordination mechanisms changed from functional to cross-functional. Orlikowski (1996) argues that the introduction of the new customer support system in the organization triggered the process of organizational transformation but that the transformative change actually happened through situated actions and improvisations as the organizational actors were enacting the new IT system into their work routines (see also Vaast \& Walsham, 2005; Leonardi \& Barley, 2010). Both academics and practitioners have been struggling for a long time to understand how the implementation, and in particular the use of a new IT system transform organizations (Leonardi \& Barley, 2010; Besson \& Rowe, 2012).

IS scholars who study IT-enabled OT from constructivist perspectives, generally hold that organizational change emerges from an ongoing stream of social actions in which actors respond to an IT system's affordances and constraints (Leonardi \& Barley, 2010). Leonardi and Barley (2010) have approached IT-enabled OT from five coherent social constructivist perspectives: perception, interpretation, appropriation, enactment, and alignment to explain the social construction of a newly implemented IT system. They argue that the five constructivist perspectives build a robust approach to investigate how actors and an IT system interact with each other in creating a new social reality in the organization.

However, only a few studies have combined different constructivist perspectives to study the phenomenon of IT-enabled OT in a holistic and integrated manner (Orlikowski, 1996; Leonardi, 2007; Leonardi \& Barley, 2010; Besson \& Rowe, 2012). Leonardi and Barley (2010) found only two studies, in which the enactment perspective on situated actions and improvisations is linked with the alignment perspective (Orlikowski, 1996; Leonardi, 2007). In addition, most studies are tilted towards studying the evolution of social processes and ignore the evolution of the IT system in the implementation process (Leonardi \& Barley, 2010). The evolution of the IT system in IT-enabled OT however requires due consideration (Leonardi, 2009) as also highlighted by Orlikowski and Iacono (2001) when desperately seeking the "IT" in IS research. In order to address these issues, this paper proposes a conceptual framework that depicts IT-enabled OT as a coevolution process of organizational routines and a new IT system.

The conceptual framework considers an organization as a collection of routines (Winter, 2003; Felin et al., 2012; Deken et al., 2016), where an organizational routine is a repetitive, 
recognizable pattern of interdependent actions, carried out by multiple actors (Feldman \& Pentland, 2003). It also considers an IT system as a collection of affordances and constraints (Leonardi, 2011). A technology affordance refers to an action potential, that is, what actors can do with an IT system in their work routines whereas a constraint addresses the way an IT system may be holding back the actors in achieving their goals (Leonardi, 2011; Seidel, Recker \& Brocke, 2013; Verhulst \& Rutkowski, 2017). The purpose of defining IT-enabled OT as a coevolution process is to investigate how the new IT system shapes organizational routines, as well as how the evolution of routines shapes the features and functions of the new IT system (Leonardi, 2009). Unlocking the coevolution process of organizational routines and a new IT system, allows us to study IT-enabled OT comprehensively, by combining the five social constructivist perspectives in a systematic manner. The conceptual framework provides a new approach to study the phenomenon of IT-enabled OT holistically, by enabling research to investigate how actors perceive, interpret, appropriate, and enact the new IT system in their work routines as well as how they align the new system and these routines with the social order and the structures of the organization. This enhances our understanding of how change unfolds in an organization during the implementation and use of a new IT system.

The next section describes our approach for reviewing the existing IS literature on IT-enabled OT. We then present, in the third section, the theoretical background of IT-enabled OT particularly highlighting the five social constructivist perspectives on IT system implementation and the concept of organizational routines. The fourth section then conceptualizes IT-enabled OT as a coevolution process of organizational routines and a new IT system. The fifth section discusses and justifies our ontological position with regard to the proposed framework to study IT-enabled OT. Finally, the sixth section summarizes our work and concludes with a discussion of limitations and a call for future research to empirically validate and refine the proposed framework.

\section{A Hermeneutic Approach for Conducting the Literature Review}

We used a hermeneutic approach to review the existing IS literature and to understand how the concept of IT-enabled OT evolved over the last decade as a basis for the development of a framework for IT-enabled OT. The hermeneutic approach is an iterative approach for conducting a literature review, which includes the following phases: searching, reading, mapping and classifying, critical assessment, and argument development (Boell \& CecezKecmanovic, 2014). In the first hermeneutic cycle, we identified four paradigms of IT-enabled OT have been identified: a) planned change models b) technological imperative c) punctuated equilibrium (PE) models d) social constructivist perspectives (Orlikowski, 1996; Leonardi \& Barley, 2010). In the second hermeneutic cycle, we dismissed the first 3 paradigms because they do not consider emergent change, which is relevant in today organizations (Orlikowski, 1996). The third hermeneutic cycle then focused on the social constructivist perspectives: perception, interpretation, appropriation, enactment, and alignment as distinguished by Leonardi and Barley (2010). These authors also identified two major issues in the application of constructivist perspectives to investigate the phenomenon of IT-enabled OT. First, different constructivist perspectives are associated with the construction of different social processes, and hence operate at different levels of analysis (Leonardi \& Barley, 2010). Second, extant studies based on social constructivist perspectives are not considering the evolution of the new IT system itself in the implementation process. To overcome these issues, the fourth hermeneutic cycle focused on the coevolution of organizational routines and a new IT system 
(Pentland \& Feldman, 2005; D'Adderio, 2008; D'Adderio, 2011), which resulted in the development of a new conceptual framework to study the phenomenon of IT-enabled OT in a systematic manner.

\section{Theoretical Background}

\subsection{Four theoretical Perspectives on IT-enabled OT}

The theoretical perspectives on IT-enabled OT can be classified into four paradigms (Orlikowski, 1996; Leonardi \& Barley, 2010): a) planned change models b) technological imperative c) punctuated equilibrium (PE) models d) social constructivist perspectives.

\begin{tabular}{|c|c|c|c|c|}
\hline OT Paradigms & $\begin{array}{l}\text { Planned } \\
\text { Change Models }\end{array}$ & $\begin{array}{l}\text { Technological } \\
\text { Imperative }\end{array}$ & $\begin{array}{l}\text { Punctuated } \\
\text { Equilibrium } \\
\text { Models }\end{array}$ & $\begin{array}{l}\text { Social Constructivist } \\
\text { Perspectives }\end{array}$ \\
\hline Philosophical stance & Voluntarism & Determinism & - & Social Constructivism \\
\hline Change enablers & Actors & IT & Actors & Actors' Interaction \& IT \\
\hline Change type & $\begin{array}{l}\text { Small or Big/ } \\
\text { Short or Long }\end{array}$ & - & $\begin{array}{l}\text { Episodic \& } \\
\text { Radical }\end{array}$ & Continuous \& Cumulative \\
\hline Change process & $\begin{array}{l}\text { Sequential \& } \\
\text { Time bound }\end{array}$ & - & $\begin{array}{l}\text { Sequential \& } \\
\text { Time bound }\end{array}$ & Non-linear \& Ongoing \\
\hline Notion of emergence & No & No & No & Yes \\
\hline
\end{tabular}

Table 1. The Paradigms of Organizational Transformation

The planned change model's paradigm presumes that people deliberately initiate and implement changes to improve the performance of the organization and make it fit with the environment (Dunphy \& Stace, 1988). Planned change models are criticized for their high reliance on the rationality of managers directing the change and treating it as a separate event from the ongoing processes of organizing (Orlikowski, 1996). The technological imperative paradigm considers an IT system as the main driver of organizational change, so that the adoption of a new IT system creates predictable changes in the structure and work practices of an organization (Huber, 1990). The technological imperative paradigm is mainly criticized for ignoring the role of actors to explore, learn and adjust to different organizational situations. The punctuated equilibrium models paradigm posits that organizations are evolving through relatively long periods of stability in their basic patterns of activity, which are punctuated by relatively short periods of revolutionary change (Gersick, 1991, p. 12; Romanelli \& Tushman, 1994). The punctuated equilibrium models paradigm is mainly criticized for its assumptions of moving the organization to some sort of stable state or equilibrium state, whereas contemporary organizations are characterized by frequent change, learning, flexibility and self-organizing (Orlikowski, 1996).

The planned change models, technological imperative and punctuated equilibrium models paradigms do not consider the phenomenon of emergent change (Orlikowski, 1996; Leonardi \& Barley, 2010). Emergent change is relevant because unprecedented environmental, technological and organizational developments facilitate patterns of organizing which cannot be prescribed by prior plans or intentions.

The social constructivist perspectives paradigm uncovers the notion of emergent change during the implementation and use of a new IT system. Scholars who study IT-enabled OT from constructivist perspectives generally hold that organizational change emerges from an 
ongoing stream of social actions in which actors respond to an IT system's affordances and constraints (Leonardi \& Barley, 2010). The introduction of a new IT system triggers the process of organizational transformation, but the actual change happens over a period of time through situated actions and ongoing improvisations (Orlikowski, 1996). The focus of this paradigm is that change may not always be as planned, inevitable, or discontinuous as we expect; rather it is realized through ongoing variations and adjustments when the actors try to accommodate a new IT system into their work routines (Hutchins, 1991; Orlikowski, 1996; Leonardi \& Barley, 2010). Table 1 provides a summary of these 4 paradigms.

\subsection{Five Social Constructivist Perspectives on IT-enabled OT}

Leonardi and Barley (2010) have approached IT-enabled OT from five coherent social constructivist perspectives: perception, interpretation, appropriation, enactment, and alignment to explain the social construction of a newly implemented IT system. They put forward that the perspectives focus on different phases of the implementation of a new IT system. They also contend that these perspectives build a comprehensive approach to study how an organization and an IT system interact with each other in creating a new social reality in the organization.

The perception perspective focuses on adoption and seeks to explain why actors come to share similar perceptions about the usefulness of a new IT system. The perception perspective also investigates how shared perceptions lead to the acceptance or rejection of the new IT system (Leonardi \& Barley, 2010). The social construction of the new IT system occurs through the convergence of attitudes, values, and beliefs among the actors of a new IT system (Vishwanath, 2006). The social construction process ceases once actors have made an initial decision to adopt the new IT system (Rice \& Aydin, 1991; Leonardi \& Barley, 2010). The decision to continue further use of the new IT system depends on users' evaluation of the IT system's performance.

\begin{tabular}{llllll}
\hline & Perception & Interpretation & Appropriation & Enactment & Alignment \\
\hline $\begin{array}{l}\text { Implementation } \\
\text { phase of new IT }\end{array}$ & Adoption & Use & Use & Use & Adaptation \\
$\begin{array}{l}\text { system } \\
\text { Social }\end{array}$ & $\begin{array}{l}\text { Convergence } \\
\text { of attitudes, } \\
\text { beliefs, and } \\
\text { values }\end{array}$ & $\begin{array}{l}\text { Transference of } \\
\text { knowledge \& }\end{array}$ & $\begin{array}{l}\text { Emergence of } \\
\text { patterns of }\end{array}$ & $\begin{array}{l}\text { Situated } \\
\text { improvisations }\end{array}$ & $\begin{array}{l}\text { Reconfigur- } \\
\text { ation of roles }\end{array}$ \\
& Schemas & $\begin{array}{l}\text { deviations \& } \\
\text { conformity }\end{array}$ & $\begin{array}{l}\text { \& Evolution of } \\
\text { \& relation- } \\
\text { ships }\end{array}$ \\
\hline
\end{tabular}

Table 2. The Social Constructivist Perspectives of Organizational Transformation (adapted from Leonardi \& Barley, 2010)

The interpretation perspective asks how people draw on familiar frames to make sense of and interpret the new IT system in use in unfamiliar situations (Orlikowski \& Gash, 1994; Leonardi \& Barley, 2010). According to Orlikowski and Gash (1994), frames are built up repertoires of tacit knowledge that an actor uses to impart meaning in an ambiguous situation. Frames implicitly guide actors to make sense of uncertain situations and then act accordingly. The social construction involves the transfer of knowledge and the modification of previously held frames to cope with new situations during the implementation and use of a new IT system (Hsiao, Wu, \& Hou, 2008). 
The appropriation perspective investigates whether people use the new IT system as it was designed and intended by the designers (Leonardi \& Barley, 2010). According to Poole and DeSanctis (1990), the design of an IT system has two aspects: a) spirit, the general goals, and attitudes that the IT system aims to promote; b) structural features, the technical features and functions of the IT system. The designers inscribe affordances and constraints into an IT system to encourage certain patterns of actions and behaviours (D'Adderio, 2011). Actors appropriate the features and functions of the new IT system consistent or inconsistent with the designers' intentions (Leonardi \& Barley, 2010). The appropriation perspective is silent and gives rare explanations of the situated accounts why actors deviate and use an IT system in an unanticipated manner (Leonardi \& Barley, 2010), which is the focus of the enactment perspective.

The enactment perspective studies how actors use a new IT system in their work but focuses on the evolution of work practices rather than cognitions or norms (Leonardi \& Barley, 2010). Weick (1979) introduced the concept of enactment into organization studies as a way of emphasizing the idea that organizing is an activity and that organizational actors wittingly and unwittingly craft organizations as they try to make sense of and respond to their environments. The enactment perspective narrates how the institutional embedding of an IT system into the social system takes place (Berente et al., 2008). The enactment perspective aims at identifying micro-level processes, which translate the working logic of the new IT system into the work practices and routines of the implementing organization (Orlikowski, 1996; Leonardi \& Barley, 2010). The enactment perspective ignores the implications of macro-level structures with respect to the use of the new IT system, which is the focus of the alignment perspective (Leonardi \& Barley, 2010).

The alignment perspective focuses on the adaptation of an IT system, in which the social order of an organization and the newly implemented IT system reconfigure and adjust to each other (Leonard-Barton, 1988; Sabherwal, Hirschheim, \& Goles, 2001). The alignment perspective investigates how the social order of an organization shapes the use of a new IT system and how the use of a new IT system alters an existing social order (Leonardi \& Barley, 2010). The central theme of the alignment perspective is to examine how roles and relationships change during the implementation of a new IT system (Barley, 1990).

The social constructivist perspectives are summarized in table 2. As stated above, IS scholars have been facing two major challenges when applying social constructivist perspectives to study the phenomenon of IT-enabled OT.

First, different constructivist perspectives are associated with the construction of different social processes, and hence operate on different levels of analysis (Leonardi \& Barley, 2010). The perception perspective focuses on the convergence of attitudes, beliefs, and values; the interpretation perspective focuses on the transfer of knowledge; the appropriation perspective focuses on the patterns of deviation and conformity; the enactment perspective focuses on the evolution of work practices; the alignment perspective focuses on the reconfiguration of roles and relationships (Leonardi \& Barley, 2010). The investigation of IT-enabled OT demands however to examine the construction and evolution of all social processes simultaneously (Leonardi \& Barley, 2010; Besson \& Rowe, 2012) as only then IT-enabled OT can be understood in a holistic and integrated manner. So far only a few studies have combined some of the different social constructivist perspectives to investigate the phenomenon of IT-enabled OT in 
a comprehensive manner (Orlikowski, 1996; Leonardi, 2007; Leonardi \& Barley, 2010; Besson \& Rowe, 2012).

Second, extant studies based on social constructivist perspectives are skewed towards studying social processes during the implementation, and in particular the use of a new IT system (Leonardi \& Barley, 2010). It is however also important to explore how the new IT system itself evolves during the implementation process (Leonardi, 2009). These issues can be resolved to a great extent if we conceptualize IT-enabled OT as a coevolution process of organizational routines and a new IT system (Pentland \& Feldman, 2005; D'Adderio, 2008; D'Adderio, 2011). This will enable research to holistically study the five social constructivist perspectives in a single organizational setting.

\subsection{The Concept of Organizational Routines}

Organizations accomplish much of their work through executing established routines (Feldman, 2000), where an organizational routine is a repetitive, recognizable pattern of interdependent actions, carried out by multiple actors (Feldman \& Pentland, 2003). Organizational scholars investigate routines from two different perspectives, the capability, and the practice perspective. The capability perspective focuses on routines as whole entities whereas the practice perspective focuses on the parts of routines (Parmigiani \& HowardGrenville, 2011). The capability perspective is mainly concerned with the purpose and impact of routines on organizational performance (Dosi, Faillo, \& Marengo, 2008) whereas the practice perspective focuses on how organizational routines operate and how they are (re)produced or changed as people enact them (Parmigiani \& Howard-Grenville, 2011). The practice perspective is grounded in practice theory, which describes how everyday practices are accomplished, reinforced, or changed (Feldman \& Orlikowski, 2011).

Practices are the recurrent, materially bounded and situated actions engaged in by actors of the organization (Orlikowski, 2002; Vaast \& Walsham, 2005). Bourdieu (1990) defines a practice as shared actions performed by a group of actors. At the most micro-level, a gesture, and a speech act, are both practices (Collins, 1981). They are microsocial actions through which work is carried out. At the meso-level a practice consists of multiple microsocial actions that together constitute a socially recognizable practice (Orlikowski, 2000). Negotiation and interaction among actors represent practices which occur at a meso-level (Barley, 1986). Practices can be conceptualized as the aggregate of meso-level actions into macrosocial categories such as an organizational routine (Feldman \& Pentland, 2003). For example, the hiring routine can be seen as a combination of meso-level actions such as screening applicants, conducting interview, and negotiating contracts.

The emphasis of the practice perspective is to uncover the internal working of routines (Feldman \& Pentland, 2003) to open the black box of an organizational routine and to reconceptualise it as being made of two interacting parts - its ostensive aspects and its performative aspects. The ostensive aspect represents the ideal or schematic form of the routine. It is the routine in principle (Feldman 2003; Feldman \& Pentland, 2003). The performative aspect captures specific actions, by specific people, at specific times and places (Feldman \& Pentland, 2003). It is the routine in practice. Initially, when a routine is put into practice the actors use the ostensive aspect to guide their actions, refer to the pattern of interactions and evaluate the performance outcomes (Feldman \& Pentland, 2003). When the routine does not produce the outcome as expected actors bring about variations in the performance of the routine through adjustments, accommodations, and improvisations 
(Feldman \& Orlikowski, 2011). This causes the actors to modify and recreate the ostensive aspects of the routine. Hence, there are recursive relationships between the two aspects; both are mutually constitutive and essential for the development, evolution, and adaptation of organizational routines (Feldman \& Pentland, 2003; Pentland \& Feldman, 2005).

Organizational routines act as a key mechanism to capture change in the organization by investigating how change is occurring to the underlying practices in an organizational routine (Nelson \& Winter, 1982). Variation and selective retention of patterns of actions bring change to the performance of an organizational routine. Pentland and Feldman (2005) conceptualize an organizational routine as a generative system with internal structure that can produce a wide variety of performances depending on the contextual situations. Examining the internal structure of a routine involves considering the interactions between ostensive aspects of a routine, performative aspects of a routine, and the artifacts that play a fundamental role in influencing both the aspects of a routine (D'Adderio, 2008). Uncovering the interactions between ostensive aspects, performative aspects and artifacts provides a sound foundation to understand change in an organization (D'Adderio, 2011). IT systems as artifacts are key in the production and reproduction of routines; they directly influence the rate and direction of change in the organizational routines and therefore their evolution and adaptation (D'Adderio, 2011).

\section{IT-enabled OT as a Coevolution Process}

\subsection{A Conceptual Framework for IT-enabled OT as a Coevolution Process}

IT systems constitute an important category of technological artifacts and play an important role to accomplish work in contemporary organizations ( $\mathrm{D}^{\prime}$ Adderio, 2011). They enable as well as constrain the performance of organizational routines (D'Adderio, 2008) and enrolled as artifacts in the composition of an organizational routine, play a fundamental role in its creation and evolution (Pentland \& Feldman, 2008). Figure 1, adapted from Pentland and Feldman (2008), depicts how artifacts, of which IT systems are an instance, are represented by and influence both the ostensive and performative aspects of an organizational routine.

As stated above the ostensive aspects of an organizational routine as partly inscribed in an IT system enable and constrain the performative aspects of that routine which in turn create and recreate its ostensive aspects. According to Orlikowski (2002), IT systems as technological artifacts embody affordances and constraints to structure work, extend interactions, increase visibility of information and actions, enable, and constrain the ability of actors, regulate access to resources, and facilitate knowledge sharing and accumulation. Affordances and constraints are inscribed into an IT system in the form of features and functions to encourage and impose certain patterns of actions and behaviours in the organization (Grint \& Woolgar, 2013).

The notion of inscription indicates that an actor's assumptions, intentions and working logic are embedded in the IT system (Latour, 1992) which directly influence the organizational routines in which they are involved. This means that an organizational routine is not simply actor-embodied but instead distributed across actors and IT systems (Hutchins, 1995). Hence, an IT system also acts as a model or a partial representation of organizational routines, containing selective and codified configurations of the ostensive aspects of routines as their artifactual representation (D'Adderio, 2011). 


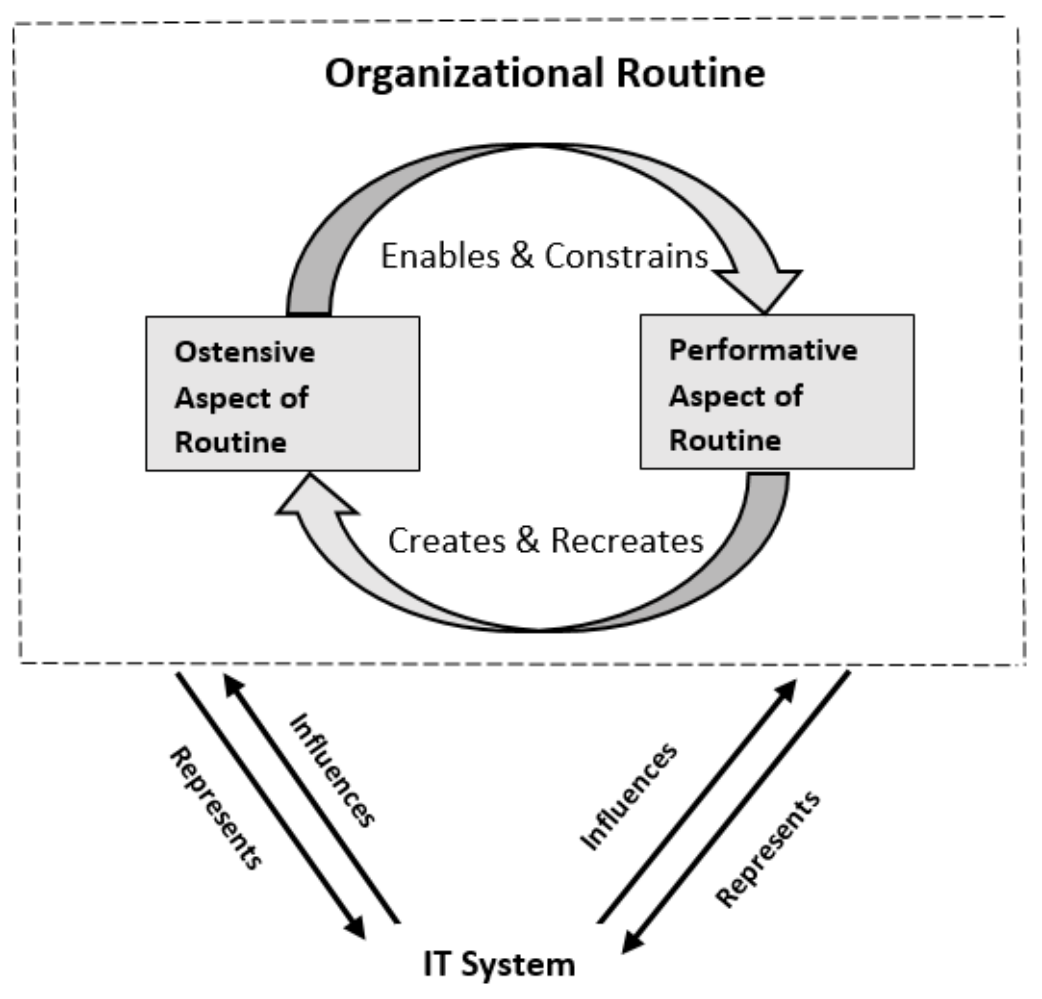

Figure 1. The Relation of an IT System and an Organizational Routine (adapted from Pentland $\mathcal{E}$ Feldman, 2008)

The concept of artifactual representation enables researchers to investigate change in the organization by unlocking the coevolution process of organizational routines and the newly implemented IT system. D'Adderio (2011) argues that uncovering the reciprocal interactions between both aspects of organizational routines and an IT system is key to understand how routines and an IT system coevolve with each other in IT-enabled OT. The interactions between ostensive aspects of routines and an IT system are critical to be investigated to understand how working logic and abstract patterns of actions are inscribed into an IT system (Pentland \& Feldman, 2005; D'Adderio, 2008) and how the IT system shapes the two aspects. This enhances the understanding of how change is occurring to the IT system in the coevolution process (Goh et al., 2011). Studying the interactions between the performative aspects of routines and an IT system is critical to understand how actors use the IT system when performing organizational routines and how an IT system shapes the performances of such routines (Pentland \& Feldman, 2005; D'Adderio, 2008). This enhances the understanding of how change is occurring to the organizational routines during the implementation, adoption, use, and adaptation of a new IT system.

Figure 2 depicts the coevolution process of organizational routines and a newly implemented IT system, adapted from D'Adderio (2011) and Lehrig et al. (2015). It is a refinement of Pentland and Feldman's (2008) model shown in figure 1.

The coevolution process is triggered as the actors start using a new IT system. When actors do not get the desired performance from the use of the new IT system, they either change the organizational routines or the new IT system. The perception of the system's affordances triggers actors to alter their work routines while the perception of constraints leads the actors to request the modification of the new IT system (Leonardi, 2011). However, as resources and 
efforts are required to change the IT system while in operation (D'Adderio, 2008) most of the time actors try to accommodate the new IT system in their work routines through interpretation, appropriation, and enactment (Leonardi, 2011). Through interpretation, the actors draw on past technological frames to understand and use the new IT system in ambiguous situations (Orlikowski \& Gash, 1994). In appropriation, the actors use the new IT system in a different way and choose its features for the purposes other than what were the designers' intentions (Watson et al., 1988). In enactment, the new IT system is locally adopted through situated, planned as well as unplanned actions (Orlikowski, 1996). The appropriation and enactment of a new IT system not only affect the individual routines but also shift and reconfigure the roles and relationships in between interconnected routines and the new IT system (Leonardi \& Barley, 2010; Goh et al., 2011). These shifts of roles and relationships between routines, and between routines and the new IT system impact the social order and structures in an organization and actors align both routines and the IT system with the possibly changed social order and the structures of the organization.

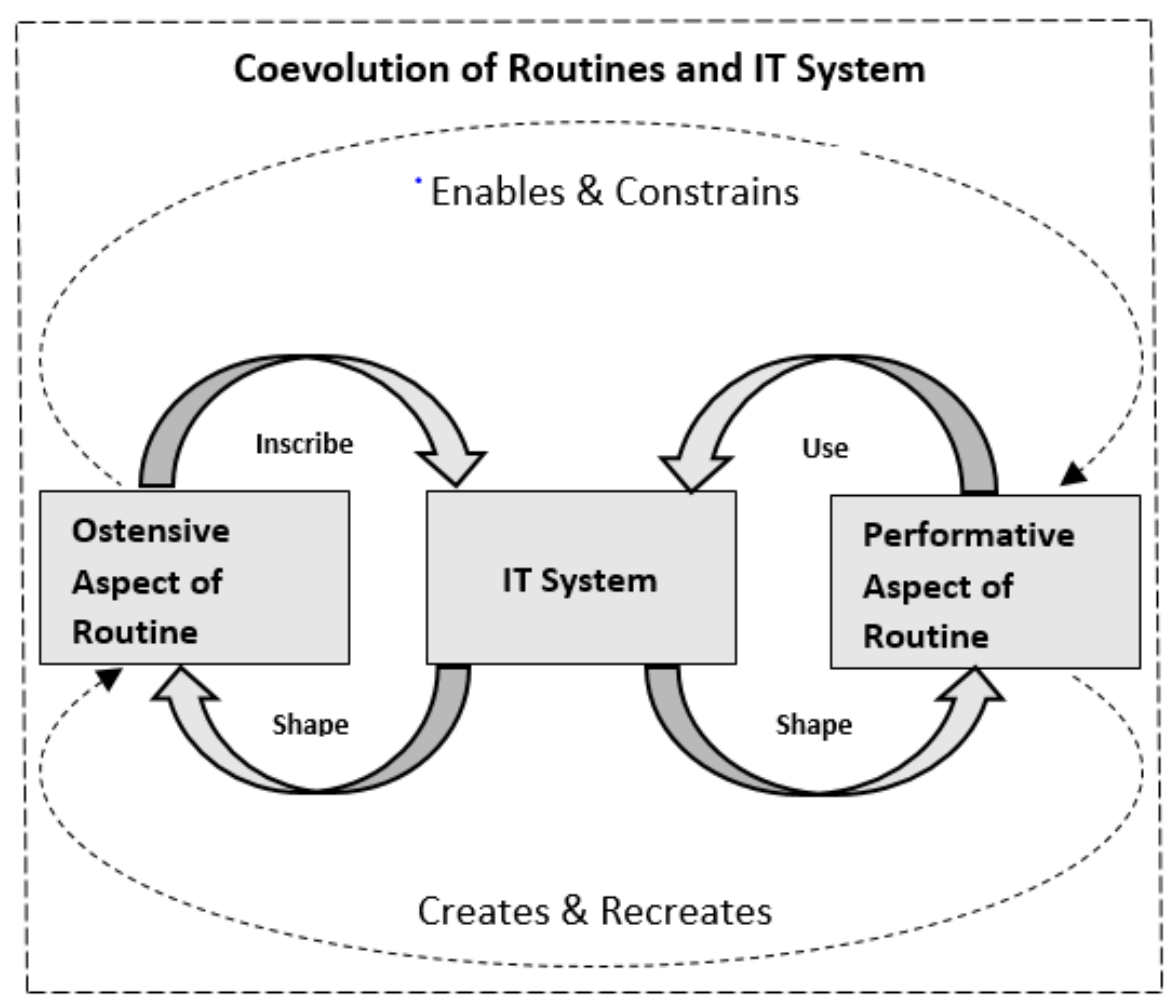

Figure 2. Coevolution of Routines and an IT System (adapted from D'Adderio, 2011; Lehrig et al., 2015)

Figure 3 below is a further extension of figure 2 and incorporates the five social constructivist perspectives. It depicts our conceptual framework and emphasizes their role for understanding IT-enabled OT as a coevolution process of organizational routines and a new IT system. 


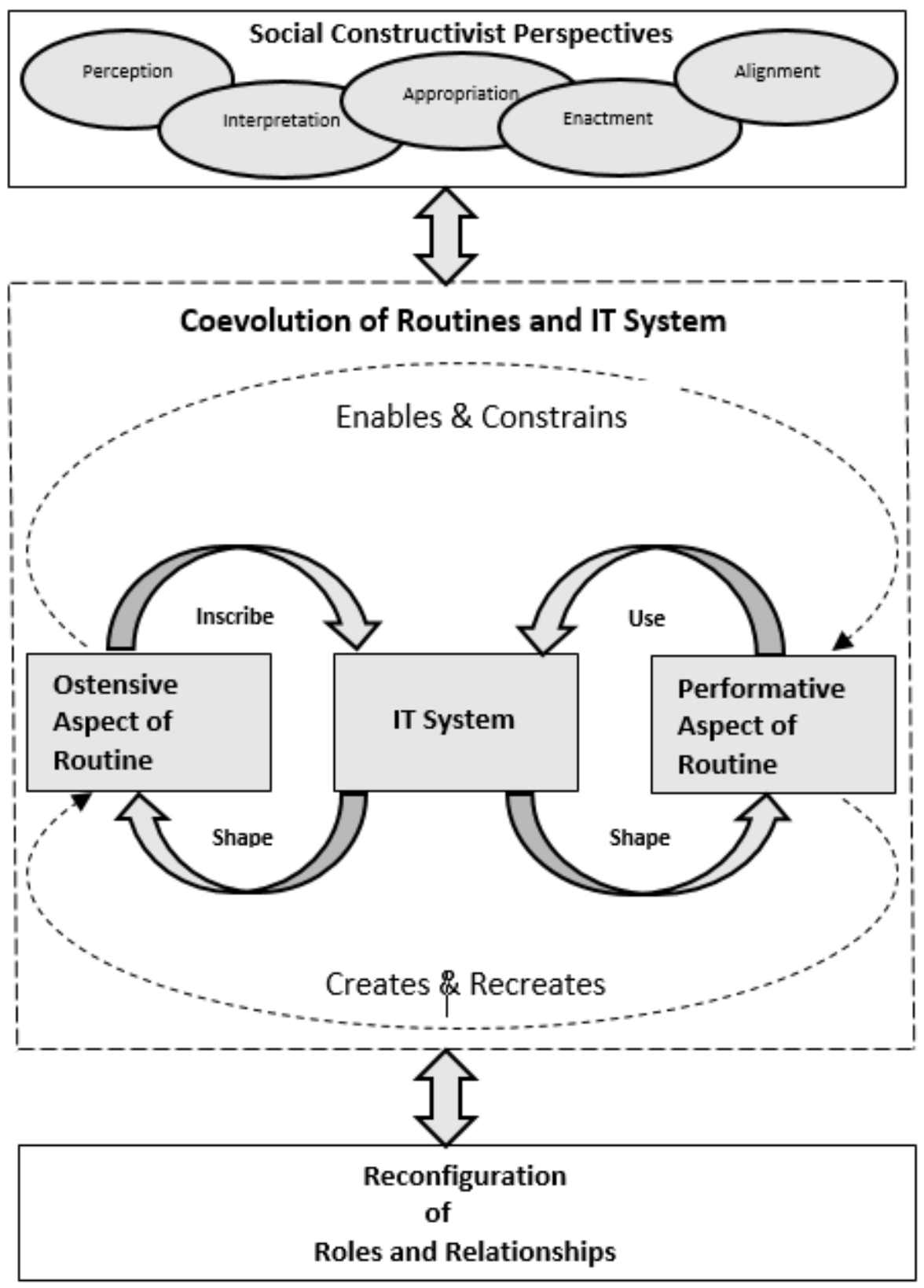

Figure 3. A Framework of IT-enabled Organizational Transformation

The framework understands an organization as a collection of routines, where a routine is a repetitive, recognizable pattern of actions, carried out by multiple actors. An organizational routine is composed of two interacting parts - its ostensive aspects and its performative aspects. The ostensive aspects of routines are abstract patterns of actions, which are partially also inscribed into a new IT system. The performative aspects are the specific actions, taken by the specific actors to accomplish work with the use of a new IT system. The IT system as a technical artifact influences and mediates both the ostensive and performative aspects of organizational routines. The IT system embodies affordances and constraints in the form of features and functions to encourage and impose certain patterns of actions in the organization. The IT system as a collection of affordances provides new possibilities of actions and enables the actors through its use to shape the performance of their work routines. The actors accommodate the features and functions of a new IT system by altering and adjusting the 
actions in their work routines. Problems and issues emerge during the use of a new IT system, which (re)shape the understanding of the actors about their work routines. If the new IT system does not produce the expected outcome actors bring about variations in the performance of the routines through adjustments, accommodations, and improvisations. This enhances the understanding of the actors and causes them to (re)create the ostensive aspects of their work routines. The use of a new IT system not only enables new possibilities of actions but also constrains the actors to carry out certain actions. To overcome the constraints of a new IT system the actors have two options: either to change the work routines or to change the functions and features of the newly implemented IT system. In case of the first option, the actors manoeuvre the use of a new IT system and use it in an unintended manner whereas in the 2 nd case new features and functions are requested to be inscribed in the IT system.

The framework further elaborates the reciprocal interactions between different aspects of organizational routines and a new IT system from the five social constructivist perspectives. To understand the early phase of IT system implementation, the framework focuses on how the actors perceive the features and functions of a new IT system in the work routines. Uncovering the perception of a new IT system is key to understand why some features and functions are adopted while others are rejected. The perception of a new IT system influences the adoption decisions, which have implications for the interpretation, appropriation, and enactment of a new IT system.

The framework explores how actors make sense of and interpret the new IT system in their work routines. In ambiguous situations or in the absence of adequate training the actors interpret a new IT system in their work routines in terms of familiar IT systems that they have worked with in the past. Uncovering the interpretation of an IT system is important because it affects the ways through which a new IT system is to be appropriated and enacted by the actors. The framework also comprises an analysis of the appropriation of a new IT system and particularly focuses on how and why actors deviate from the original design of a new IT system. The choice of using a new IT system either in intended or unintended manner causes the actors to follow different actions paths and influence the evolution of organizational routines. Along with appropriation, the framework also uncovers the enactment of a new IT system to understand how actors actually embed the new IT system in their work routines through planned as well as unplanned actions. As unexpected and emergent events appear during the enactment process then how actors cope with such situations and how they adjust the actions in the work routines is part of this perspective.

New work practices emerge during the appropriation and enactment of a new IT system, which challenge the existing roles and relationships of the routines and actors in the social order and the structures of the organization. This moves the focus of the framework to the adaptation phase to investigate how roles and relationships (re)align with the use of a new IT system. If roles and relationships are altered and social order and structures are changed this perspective studies how actors then carry out further appropriation and enactment cycles to align the performance of the work routines with the new social order and new organizational structures. If roles and relationships remain unchanged the actors might use the new IT system as is. The relationship between enactment and alignment is critical to be investigated to understand how the structure of the implementing organization is either enabling or constraining the coevolution of organizational routines and the new IT system. 
Our proposed conceptual framework offers a mechanism to explore the complex interactions between the different aspects of organizational routines and a new IT system in a systematic manner. The framework allows to understand IT-enabled OT as a coevolution process of organizational routines and a new IT system in a holistic and integrated manner.

\subsection{Understanding IT-enabled OT as a Coevolution Process through the proposed Framework}

In the previous section we developed and explained our framework largely based on theoretical considerations. In the following we illustrate its scope as well as its conceptual and analytic strength with selected empirical examples from the research literature on IT-enabled OT. These examples mostly focus on individual perspectives and aspects of the OT process, sometimes covering and combining several of them, but none is based on a comprehensive framework such as ours which further underpins the need for a holistic approach to studying and achieving a deeper understanding of the phenomenon.

When a new IT system is introduced in an organization, actors neither fully employ the newly implemented IT system in their work routines nor do they totally by-pass the new IT system. Boudreau and Robey (2005) found in a study of ERP system implementation in a US government organization that actors initially were not willing to break their old routines and avoided the new IT system as much as possible. Later, after the organizational routines and the new IT system had passed through a process of coevolution the ERP system was adopted.

Goh et al. (2011) presented an account of the coevolution of organizational routines and an IT system in their study of a Computerized Documentation System (CDS). The implementation of the CDS replaced paper-based patient charts/notes with digital notes in the 'Rounding Routine' in a healthcare organization. The CDS enabled physicians to view the patient documentation from anywhere and to give advice remotely rather than physically having to go to the patient's bed to check the treatment chart. The implementation of CDS shaped the performative aspects of the 'Rounding Routine' in the healthcare organization. The digital notes functionality of the CDS provided new possibilities for actions but also constrained the actors to carry out certain actions. For instance, no field was available in the CDS to record the communication between physicians which had been part of their work practices and the existing social order and structure in the organization. This issue shaped and (re-)created the understanding of this ostensive aspect of the 'Rounding Routine' as it was reported to the technical team and a new feature was inscribed in the CDS accordingly. With the ostensive aspects of the routine partially inscribed in the IT systems the CDS also enabled the physicians to get updated information about a patient by simply clicking on various sections of an etreatment chart as part of the 'Rounding Routine'. The new pattern of actions was perceived as a significant improvement over the paper-based reporting in terms of efficiency and decision making. However, the physicians proposed further enhancements to get a consolidated view of all patient information in one place by using a single click. The need of the aggregated patient report (re)shaped the actors' understanding of the ostensive aspects of the 'Rounding Routine', and hence they requested and received a new feature to be inscribed in the CDS which subsequently further shaped the performative aspects of this routine.

This example shows that unlocking the coevolution process of organizational routines and an IT system is key to understand IT-enabled OT by investigating how actors perceive, interpret, appropriate, and enact the new IT system in their work routines, as well as how they align the 
new system and these routines with the social order and structure of the organization (Pentland \& Feldman, 2008; Leonardi \& Barley, 2010; D'Adderio, 2011).

As actors are not able to achieve their expected results from the use of a new IT system, they have two options: either to change their work routines or to request and get a change of the functions and features of the newly implemented IT system.

We explained above that the perception of the new IT system as a collection of affordances triggers actors to alter their work routines to make fuller use of the new IT system (Leonardi, 2011) and that the perception of the new IT system as a bundle of constraints leads the actors to ask for changes to be made to the technical features and functions of the new IT system (Leonardi, 2011). Goh et al. (2011) argue that the healthcare staff in their case study perceived the new IT system to afford their work further by providing new possibilities of actions. This perception caused the healthcare staff to adjust their work routines to accommodate the features and functions of the new IT system. On the other hand, the physicians perceived that the new IT system constrained their work routines and asked for the development of new features and functions to be included in the IT system. The perception of affordances and constraints leads actors to either change organizational routines or the IT system, but research suggests that often organizational routines are changed (Leonardi, 2011) underlining the importance of the perception perspective. As stated earlier this is due to the inflexibility of an IT system to be changed during operation and because resources and efforts are required to modify, test, and deploy changes to a new IT system (D'Adderio, 2008).

During the use of an IT system organizational actors employ three interrelated techniques, namely interpretation, appropriation, and enactment (Leonardi \& Barley, 2010) which (might) lead to both modifications of the organizational routines and of the IT system.

Through interpretation, actors make sense of the new IT system by drawing on technological frames imported from other domains (Hsiao, $\mathrm{Wu}, \& \mathrm{Hou}, 2008)$. The actors attempt to situate their thoughts about actions in terms of familiar IT systems that they had worked with in the past. For instance, Orlikowski and Gash (1994) studied the implementation of Lotus Notes in a consulting firm. The consultants interpreted the new IT system in light of the existing applications, which they were using individually. As a consequence, they utilized the new IT system for accomplishing individual tasks like e.g., sending email in contrast to the intended purpose of the system to facilitate and enhance the collaboration among them. This example shows how the interpretation of a new IT system and of its interplay with the ostensive and performative aspects of the organizational routines affects the ways in which a new system, in this case contrary to its original purpose, is appropriated and enacted by the actors (Leonardi \& Barley, 2010).

In appropriation, the actors chose whether to use the new IT system as designed or to deviate from the IT system by using its features and functions for purposes other than those the designers intended (Watson, DeSanctis, \& Poole, 1988). Leonardi (2007) studied a group of technicians for the first five months using a new IT system, an Information Technology Service Management (ITSM) tool, in a large US government organization. The case study revealed that the technicians carried out three rounds of technology appropriations to accommodate the new IT system into the ostensive and performative aspects of their work routines. In the first round of appropriation, the technicians used minimum features of the new IT system to record the initiation and resolution of the service tickets. In the second round, the IT system was not just used for recording tickets but also for assigning tickets to the experienced technicians 
across different departments. In the third round, the technicians realized the need to write problem resolution outlines before closing a ticket. The technicians noticed that the IT system was lacking such documentation functionality which was an important part of their organizational work routines. This was overcome by utilizing an unused field in the data entry form, where technicians added a short paragraph about the steps, they had taken to solve a user problem. This example shows that the appropriation did not require any change to the IT system but was accomplished through the use of the new IT system in a different way to accommodate for the routines which in that process (re)created and shaped the ostensive and performative aspects of their routines. This leads us to importance of the enactment perspective.

In enactment, the actors adjust the patterns of actions of the existing routines to accommodate a new IT system (Orlikowski, 1996; Pentland \& Feldman, 2008). The working logic of the new IT system is locally adopted through situated planned actions and improvisations (Orlikowski, 1996; Lyytinen et al., 2009). Orlikowski (1996) showed in her case study of a customer support system that organizational transformation occurred as a result of planned as well as unplanned enactment of a new IT system for support staff. She argues that staff enacted the new IT system by adding new actions to their work routines to fully accommodate the newly implemented IT system. For instance, the support staff included new actions in their work routines to electronically record customer complaints in the IT system while they were on the phone with the customers. She also noted that emergent situations appeared during the enactment of planned changes. For instance, when a data entry screen was incompatible with the way the customers reported complaints, the actors further adjusted their work routines to enact a changed reporting process. They wrote some information on paper while simultaneously talking to the customers and recording their complaints in the on-line system demonstrating the mutual impact of routines and IT system on each other. The unanticipated events, breakdowns, and contingencies also provided opportunities for learning, which enabled the actors to improvise their work routines.

During the interpretation, appropriation and enactment of a new IT system, actors go through a process of trial-and-error learning (Rerup \& Feldman, 2011). In the above case when unpredicted problems emerged, solutions were devised to fix them accordingly. In this respect the three phases are inherently interrelated. When actors are unable to resolve problems, themselves they approach experienced colleagues, who may quickly resolve such emerging issues based on their knowledge as they may have encountered similar kinds of technical problems in comparable settings (Aime et al., 2010).

Experienced actors are instrumental in spreading relevant knowledge in communities of IT users through informal means such as sharing tips and ad hoc documentations (Boudreau \& Robey, 2005). This type of learning is called situated learning; it helps the user community to smoothly enact the new IT system (Lave \& Wenger, 1991; Brown \& Duguid, 1991). Boudreau and Robey (2005) in their before mentioned study of the implementation of an ERP system without explicitly mentioning the three perspectives found that actors initially chose to avoid using the new IT system. The authors report that later on, through situated learning, actors increased their understanding about the new IT system and eventually progressed toward the appropriation and enactment of the new IT system.

Situated learning as an important facet in the interplay of interpretation, appropriation and enactment is not only helpful for the evolution of organizational routines as demonstrated by 
Boudreau and Robey (2005) but also contributes to the evolution of the new IT system as the study by Goh et al. (2011) showed and thus plays an important role in the coevolution of organizational routines and a newly implemented IT system.

During the design of a new IT system affordances and constraints are inscribed into the system but are only instantiated when the actors appropriate and enact the features and functions of the new IT system (D'Adderio, 2011). Problems, issues, breakdowns, exceptions, and unanticipated events occur when the actors start accommodating the new IT system in the existing work routines (Orlikowski, 1996). These problems not only provide opportunities for actors to reflect on their routines and adjust them according to the new IT system but also reflect on the affordances and constraints of the new IT system ( $\mathrm{D}^{\prime}$ Adderio, 2011). The actors provide valuable feedback and suggestions to further improve the features and functions of the new IT system reinforcing the importance of both taking appropriation and enactment into account when studying the coevolution of organizational routines and a newly implemented IT system.

New patterns of actions emerge in the organizational routines during the appropriation and enactment of a new IT system (Leonardi \& Barley, 2010). The ensuing change challenges the existing roles and relationships in the organization (Barley, 1990; Schultze \& Orlikowski, 1994). At this point, the implementation and use of a new IT system demand the reconfiguration of roles and relationships to align the new patterns of actions with the structure and social order of the organization (Leonardi \& Barley, 2010). This reinforces the innate relationship between use and adaptation, in other words the relation between the appropriation, the enactment and the alignment perspectives. For instance, Barley (1990) studied technicians in two radiology departments that had just acquired their first computerized tomography (CT) scanner. He showed that the new technology flattened the organizational structure by redefining the roles and relationships of both technicians and radiologists. If the new patterns of actions do not demand the restructuring of roles and relationships, then the use of a new IT system is unlikely to trigger any significant change in the organization (Leonardi \& Barley, 2010). In this case, existing work practices are re-enforced, and the actors may use the new IT system in ways that maintain the status quo. For instance, Edmondson et al. (2001) studied the implementation of a new IT system at sixteen hospitals and found that change did not happen in those hospitals where work practices were replicated and the new IT system supported and reinforced the traditional roles.

Roles and relationships evolve during the adaptation phase, in which the social order and structures of an organization and the newly implemented IT system reconfigure and adjust to each other (Leonard-Barton, 1988; Sabherwal, Hirschheim, \& Goles, 2001). Orlikowski's (1996) study of the organizational transformation of a software company provides an example of the relationship and impact of the enactment and the mutual alignment of IT systems, organizational routines, and organizational structures in IT-enabled OT. Likewise, Leonardi (2007) in the above cited study of the implementation of an ITSM showed how roles and relationships changed after the technicians had gone through three cycles of appropriation and enactment. In the first cycle, the functionality of the ITSM was constructed as an incident tracking tool. In this phase, the technicians sought help from their seniors in their respective departments according to hierarchical positions. The advice seeking mechanism was exactly the same as before the IT system implementation. In the second cycle, the IT system was appropriated and enacted as a project assignment tool. The IT system was not just used for 
recording a ticket but also to assign tickets to other technicians by locating them in the IT system. The actors thus sought help from many people across different departments. In the third cycle, the actors realized that the ITSM lacked details about the solutions of the problems, and hence the IT system was reconstructed as a documentation tool. The actors started to approach those technicians, who explicitly documented their expertise in the system, and hence advice was sought not only from senior technical experts but often also from junior people across the organization.

The coevolution process of organizational routines and a new IT system is a complex and emergent process, and organizations often fail to manage it in an effective manner (Goh et al., 2011). Our proposed conceptual framework appreciates the coevolution process in a systematic manner by explaining how actors perceive, interpret, appropriate, and enact the new IT system in their work routines in a situated learning process and how they align it with the social order and structures of the organization. It also explains how roles and relationships evolve during the implementation of a new IT system. It allows us to capture the interplay of social and technical dynamics that causes change in the organization. Our framework as depicted in figure 3 provides a new approach to investigate the phenomenon of IT-enabled OT as an instance of DT in a holistic and integrated manner and to study how change unfolds in an organization as a coevolution process of organizational routines and IT systems during the implementation, with its phases adoption, use, and adaptation, of a new IT system.

\section{The Ontological Positioning of the Proposed Framework}

Our framework is firmly grounded in a social constructivist perspective on IT-enabled OT. Beyond Leonardi and Barley's (2010) distinction of five social constructivist perspectives focussing on the transformative practices of perception, interpretation, appropriation, enactment, and alignment, social constructivist research can have various ontological roots (Putnam, 2015). We therefore complete the presentation of our proposed framework with a clarification and discussion of its ontological positioning.

As a reaction to technological determinism which emphasized the technical over the social by framing technology as the key driver of organizational change (Noble, 1978; Huber, 1990) social constructivism brought the social to the fore (Fulk, 1993; Zuboff, 1988). To refute technological determinism, social constructivists' studies downplayed the role of the technology in the social construction process (Leonardi \& Barley, 2010). At the most, scholars mention that an IT system activates social processes, which then construct the social phenomenon without further elaborating the technical dynamics in the process of organizing. Orlikowski and Scott (2008) have criticized constructivist studies and advocate that researchers should adopt sociomateriality for the study of technology use in the organizations. Both Orlikowski and Scott (2008) and Leonardi (2012) put forward that sociomateriality refers to that materiality, in our case the material features and functions of an IT system, gets meaning and has effects when enmeshed in a social phenomenon. Orlikowski and Scott (2008) go further and argue that materiality is not an intermittent aspect of organizational life but rather an integral part of organizing. They consider that both the social and the material are ontologically indistinct and do not exist independently, which means that there is no social that is not also material, and no material that is not also social (Orlikowski, 2007).

In line with Orlikowski and Scott (2008) we recognize that materiality is integral to organizing. Our proposed framework is thus aligned with their stance, but we conceptualize the social 
and the material as ontologically distinct. Our conceptual framework is based on the five social constructivist perspectives identified by Leonardi and Barley (2010), which inherently bring the social to the foreground. We are considering an IT system as a collection of affordances and constraints and focus on its evolution in the implementation process (Leonardi, 2011). In contrast to technological determinism, which favours the material over the social or conventional social constructivism that favours the social over the material, we aim at investigating the integration of both the social and the material as suggested by Misa (1994) and Leonardi and Barley (2008) to resolve the inadequacies of technological determinism as well as the shortcomings of applying the individual perspectives of social constructivism. Our conceptual framework emphasizes both the social and the material aspects of an IT system implementation and theorizes IT-enabled OT as a coevolution of organizational routines and a new IT system. The aim of defining IT-enabled OT as a coevolution process is to investigate how the IT system shapes routines, as well as how routines shape the new IT system (Leonardi, 2009).

In contrast to Orlikowski and Scott's (2008) approach to sociomateriality, our conceptual framework - an approach that Jones (2014) would call weak sociomateriality - considers that both the social and material are interdependent but ontologically distinct for several reasons. According to Putnam (2015) there are five different approaches to the analysis of the relation between the social and the material that have social constructivist roots. Based on a comparison of an approach's ontological position, its epistemological stance, its focal point of entry of the analysis, its understanding nature of the relationship, and of its way of managing the dialectic in the relationship, she distinguishes a) performativity b) Foucauldian analysis c) imbrication d) plenum of agencies, and e) mangle of practice as approaches to study sociomateriality. The performative approach to sociomateriality developed by Orlikowski and Scott (2008) considers the social and material as inseparable and indistinct, while the others consider the material and social as ontologically distinct but interdependent and intertwined. Our conceptual framework is closely related to the mangle of practice (Pickering, 1995; Putnam, 2015) which posits that the social and the material are distinct, but emerge together, their relationship is co-constituted through what Pickering (1995) calls a mangle and managed through a continual connection between the two.

Epistemologically, Pickering (1995) gives primacy to the association between the two but does not ascribe to a relationality that assumes that the social and the material are inherently inseparable (Orlikowski \& Scott, 2008). This resonates well with our approach to studying coevolution of organizational routines and an IT system during its implementation - its adoption, use, and adaptation - in Pickering's (1995) words the association of routines and IT system. When an IT system is implemented it disturbs the existing sociomaterial fabric of the implementing organization at the time when the new IT system is moved into a live environment (Leonardi \& Barley, 2010). According to Goh et al. (2011) and to Berente et al. (2016) studying IT system implementation in general and IT-enabled OT in particular requires to empirically unravel both the social and the technical and to look back in time to examine how the social has influenced the material features of an IT system and its effects, and how the material has shaped the social. This provides the possibility to research the activities and practices that an IT system lets actors perform in particular situations, to investigate what it does and does not let them perform, and to study the workarounds that actors have adopted to deal with in such situations (Orlikowski, 1996). 
Leonardi and Barley (2010) argue that such data provide an opportunity to identify how the material and social have recursively influenced each other over time, and how the existing sociomaterial fabric of the organization has been developed from the start of the implementation to the actual status at the time of investigation (Leonardi \& Barley, 2010). While Orlikowski and Scott (2008) conceptually emphasize the entanglement, and according to Putnam (2015) the indistinctness, of the social and the material which leaves us with the challenge to analytically distinguish between them and to impose ontological boundaries for analytical purposes (Introna, 2013), we follow Leonardi and Barley (2010) as well as Goh et al. (2011) and Berente et al. (2016). These authors advise to empirically unravel the social and the material in order to capture the social and technical dynamics distinctly and clearly to develop an understanding of how change unfolds in an organization during the implementation, in particular during the use of a new IT system, and in our research how organizational routines and a new IT system coevolve.

As stated above, the purpose of our conceptual framework is to study the coevolution of organizational routines, its underlying practices, and a newly implemented IT system at a meso-level (Feldman \& Pentland, 2003). We are not proposing the framework to study the work practices at micro-level. Positioning our framework to study at a meso-level has led us to combine the five social constructivist perspectives for understanding the phenomenon of IT-enabled OT in a comprehensive manner. Adopting Orlikowski and Scott's (2008) approach to sociomateriality would require a focus on the practices at micro-level to analytically disentangle the relative contributions of the material and the social to understand the phenomenon of IT-enabled OT. Any research combining and studying IT-enabled OT from all five social constructivist perspectives on that level of detail appears to be very challenging in practice.

Finally, we use the concept of organizational routine, as presented by Pentland \& Feldman $(2005,2008)$, as a theoretical lens to connect and integrate the five social constructivist perspectives. The conceptualization of these authors treats an IT system as a distinct artifact, which influences and shapes both the ostensive and performative aspects of an organizational routine (Pentland \& Feldman, 2005, 2008; Parmigiani \& Howard-Grenville, 2011). Such a treatment is not directly compatible with Orlikowski and Scott's (2008) approach to sociomateriality. Our immediate aim is not to extend Pentland and Feldman's $(2005,2008)$ work on routines, but to use it for the analysis of the coevolution of organizational routines and IT systems, thus our ontological positioning in the social constructivist perspective is justified.

In doing so we follow Putnam's (2015) argument for preserving the dialectical relationship between the two by holding the tensions between them in continual interplay and focussing on how the social and the material are constituted in a dialectical relationship to each other and think about the two phenomena as she puts it as "... empirically distinct, but mutually implicated; that is even though they may exist as an invisible whole, researchers need to examine them separately and dialectically to avoid privileging one pole over the other." (Putnam, 2015, pp. 706-707)

\section{Conclusion}

We are proposing a conceptual framework to theorize IT-enabled OT as a coevolution process of organizational routines and a new IT system. The conceptual framework provides a new 
approach to study the phenomenon of IT-enabled OT in a holistic and integrated manner. It combines five constructivist perspectives on the social construction of an IT system by explaining how actors perceive, interpret, appropriate, and enact a new IT system in their work routines as well as how they align the new system and these routines with the social order and structures of the organization. It enables a holistic investigation of how the IT system shapes organizational routines and how the evolution of routines shapes the features and functions of the new IT system at the same time. Such an investigation enhances the understanding of how change unfolds in an organization during the implementation, and its adoption, use, and adaptation phases of a new IT system.

The framework supports research that aims at exploring the reciprocal interactions between different aspects of organizational routines and a new IT system, to understand how change is occurring to the work practices and to the structures of an organization. Unravelling the interactions between performative aspects of routines and an IT system, as well as unravelling the interactions between the ostensive aspects of routines and an IT system deepens the understanding of how change is occurring to the routines in the organization and how change is occurring to the IT system through revision of its features and functions. The conceptualization of IT-enabled OT as a coevolution process of organizational routines and a new IT system is a theoretical contribution to the existing IS literature.

Here we have illustrated the scope and strength of the proposed framework through applying it to examples from research, which studied IT-enabled OT. We suggest that future research empirically validates and further refines the proposed conceptual framework through indepth case studies. Given that the conceptual framework is based on five social constructivist perspectives, we propose a pluralist methodological approach for the data collection and analysis (Mingers, 2001). The pluralist approach as a theory building methodology leverages the power of a multi-perspectival inquiry to develop new theory from data (Mingers et al., 2013; Müller et al., 2017). As Mingers (2001, p. 243) argues "the real world is ontologically stratified and differentiated, consisting of a plurality of structures that generate the events that occur (and do not occur). Different paradigms each focus attention on different aspects of the situation, and so multimethod research is necessary to deal effectively with the full richness of the real world".

Future case studies applying the proposed conceptual framework should e.g. jointly ask the following questions a) How does the perception of a new IT system during its adoption influence its interpretation, appropriation, and enactment in an organization during its use? b) How does the interpretation of a new IT system affect the ways in which the system is appropriated and enacted in the organizational routines? c) How are appropriation and enactment of a new IT system related and how does this relationship influence the coevolution of organizational routines and an IT system? d) How are appropriation and enactment related to the alignment of a new IT system and how does this relationship influence the coevolution of organizational routines and an IT system? e) How does the structure of the implementing organization enable or constrain the coevolution of organizational routines and an IT system? The findings from such case studies will also be helpful for practitioners to understand and manage the coevolution process of organizational routines and a newly implemented IT system in an effective manner.

Our conceptual framework is not without limitations. It supports the investigation of the phenomenon of IT-enabled OT during adoption, use, and adaptation of a new IT system first, 
after an implementation and deployment decision has been made. Furthermore, it does not take into account, actions and events which occurred and decisions which were made during the design and development of the IT system which may have implications for the IT system to be adopted, used, and adapted in one way or another. It is also imperative to take into account the way a particular IT system was chosen, why one IT system was preferred over another, and the way an IT system was designed, developed, and deployed in a certain manner. All these are important considerations which influence the social construction of a newly implemented IT system, and hence the coevolution of organizational routines and an IT system. Future studies on IT-enabled OT as a coevolution process should thus undertake research that extends the proposed framework and not only focuses on implementation and the dynamics of adoption, use, and adaptation, but adequately considers design and development dynamics to further increase the understanding of how change unfolds during IT-enabled organizational transformation.

\section{References}

Agarwal, R., Gao, G., DesRoches, C., \& Jha, A. K. (2010). Research commentary - The digital transformation of healthcare: Current status and the road ahead. Information Systems Research, 21(4), 796-809.

Aime, F., Johnson, S., Ridge, J. W., \& Hill, A. D. (2010). The routine may be stable but the advantage is not: Competitive implications of key employee mobility. Strategic Management Journal, 31(1), 75-87.

Barley, S. R. (1986). Technology as an occasion for structuring: Evidence from observations of CT scanners and the social order of radiology departments. Administrative Science Quarterly, 78-108.

Barley, S. R. (1990). The alignment of technology and structure through roles and networks. Administrative Science Quarterly, 61-103.

Berente, N., Yoo, Y., \& Lyytinen, K. (2008). Alignment or drift? Loose coupling over time in NASA's ERP implementation. ICIS 2008 Proceedings, 180.

Berente, N., Lyytinen, K., Yoo, Y., \& King, J. L. (2016). Routines as shock absorbers during organizational transformation: Integration, control, and NASA's enterprise information system. Organization Science, 27(3), 551-572.

Besson, P., \& Rowe, F. (2012). Strategizing information systems-enabled organizational transformation: A transdisciplinary review and new directions. The Journal of Strategic Information Systems, 21(2), 103-124.

Boell, S. K., \& Cecez-Kecmanovic, D. (2014). A hermeneutic approach for conducting literature reviews and literature searches. Communications of the Association for Information Systems, 34(1), 12.

Bourdieu, P. (1990). The Logic of Practice. Stanford University Press.

Boudreau, M. C., \& Robey, D. (2005). Enacting integrated information technology: A human agency perspective. Organization Science, 16(1), 3-18.

Brown, J. S., \& Duguid, P. (1991). Organizational learning and communities-of-practice: Toward a unified view of working, learning, and innovation. Organization Science, 2(1), 40-57. 
Collins, R. (1981). On the Microfoundations of Macrosociology. American Journal of Sociology, 86(5), 984-1014.

D'Adderio, L. (2008). The performativity of routines: Theorising the influence of artefacts and distributed agencies on routines dynamics. Research Policy, 37(5), 769-789.

D'Adderio, L. (2011). Artifacts at the centre of routines: Performing the material turn in routines theory. Journal of Institutional Economics, 7(2), 197-230.

Deken, F., Carlile, P. R., Berends, H., \& Lauche, K. (2016). Generating novelty through interdependent routines: A process model of routine work. Organization Science, 27(3), 659-677.

Dosi, G., Faillo, M., \& Marengo, L. (2008). Organizational Capabilities, Patterns of Knowledge Accumulation And Governance Structures In Business Firms: An Introduction. Organizational Studies, 28(8-9), 1165-1185.

Dunphy, D. C., \& Stace, D. A. (1988). Transformational and coercive strategies for planned organizational change: Beyond the OD model. Organization Studies, 9(3), 317-334.

Edmondson, A. C., Bohmer, R. M., \& Pisano, G. P. (2001). Disrupted routines: Team learning and new technology implementation in hospitals. Administrative Science Quarterly, 46(4), 685-716.

Feldman, M. S. (2000). Organizational routines as a source of continuous change. Organization Science, 11(6), 611-629.

Feldman, M. S. (2003). A performative perspective on stability and change in organizational routines. Industrial and Corporate Change, 12(4), 727-752.

Feldman, M. S., \& Pentland, B. T. (2003). Reconceptualizing organizational routines as a source of flexibility and change. Administrative Science Quarterly, 48(1), 94-118.

Feldman, M. S., \& Orlikowski, W. J. (2011). Theorizing practice and practicing theory. Organization Science, 22(5), 1240-1253.

Felin, T., Foss, N. J., Heimeriks, K. H., \& Madsen, T. L. (2012). Microfoundations of routines and capabilities: Individuals, processes, and structure. Journal of Management Studies, 49(8), 1351-1374.

Fulk, J. (1993). Social construction of communication technology. Academy of Management Journal, 36(5), 921-951.

Gersick, C. J. (1991). Revolutionary Change Theories: A multilevel exploration of the punctuated equilibrium paradigm. Academy of Management Review, 16(1), 10-36.

Goh, J. M., Gao, G., \& Agarwal, R. (2011). Evolving work routines: Adaptive routinization of information technology in healthcare. Information Systems Research, 22(3), 565-585.

Grint, K., \& Woolgar, S. (2013). The machine at work: Technology, Work and Organization. John Wiley \& Sons.

Hess, T., Matt, C., Benlian, A., \& Wiesböck, F. (2016). Options for formulating a digital transformation strategy. MIS Quarterly Executive, 15(2).

Hsiao, R. L., Wu, S. H., \& Hou, S. T. (2008). Sensitive cabbies: Ongoing sense-making within technology structuring. Information and Organization, 18(4), 251-279. 
Huber, G. P. (1990). A theory of the effects of advanced information technologies on organizational design, intelligence, and decision making. Academy of Management Review, 15(1), 47-71.

Hutchins, E. (1991). Organizing Work by Adaptation. Organization Science, 2(1), 14-39.

Hutchins, E. (1995). Cognition in the Wild. MA: MIT Press.

Introna, L.D. (2013). Epilogue: Performativity and the Becoming of Sociomaterial Assemblages, in F.-X. de Vaujany and N. Mitev (eds.), Materiality and Space, Basingstoke: Palgrave Macmillan, pp. 330-342.

Jones, M. (2014). A Matter of Life and Death: Exploring Conceptualizations of Sociomateriality in the Context of Critical Care. MIS Quarterly, 38(3), 895-925.

Latour, B. (1992). Where Are the Missing Masses? The Sociology of a Few Mundane Artifacts, in W. E. Bijker and J. Law (eds.), Shaping Technology/Building Society: Studies in Sociotechnical Change, Cambridge, MA: MIT Press, pp. 225-258.

Lave, J., \& Wenger, E. (1991). Situated Learning: Legitimate Peripheral Participation. Cambridge: Cambridge University Press.

Lehrig, T., Krancher, O., \& Dibbern, J. (2015). The Evolution of Routines under Flexible Information Technology. ECIS Proceedings, Research in Progress, 14.

Leonard-Barton, D. (1988). Implementation and mutual adaptation of technology and organization. Research Policy, 17 (5), 603-631.

Leonardi, P. M. (2007). Activating the informational capabilities of information technology for organizational change. Organization Science, 18(5), 813-831.

Leonardi, P. M. (2009). Crossing the implementation line: The mutual constitution of technology and organizing across development and use activities. Communication Theory, 19(3), 278-310.

Leonardi, P. M., \& Barley, S. R. (2008). Materiality and change: Challenges to building better theory about technology and organizing. Information and Organization, 18(3), 159-176.

Leonardi, P. M., \& Barley, S. R. (2010). What's under construction here? Social action, materiality, and power in constructivist studies of technology and organizing. Academy of Management Annals, 4(1), 1-51.

Leonardi, P. M. (2011). When flexible routines meet flexible technologies: Affordance, constraint, and the imbrication of human and material agencies. MIS Quarterly, 35(1), 147-167.

Leonardi, P. M. (2012). Materiality, Sociomateriality, and Socio-technical Systems: What do these terms mean? How are they different? Do we need them, in P.M. Leonardi, B A. Nardi and J. Kallinikos (eds.), Materiality and Organizing: Social Interaction in a Technological World, Oxford: Oxford University Press, pp. 25-48.

Lyytinen, K., Newman, M., \& Al-Muharfi, A. R. A. (2009). Institutionalizing enterprise resource planning in the Saudi steel industry: a punctuated socio-technical analysis. Journal of Information Technology, 24(4), 286-304. 
Mingers, J. (2001). Combining IS Research Methods: Towards a pluralist methodology. Information Systems Research, 12(3), 240-259.

Mingers, J., Mutch, A., \& Willcocks, L. (2013). Critical Realism in Information Systems Research. MIS Quarterly, 37(3), 795-802.

Misa, T.J. (1994). Retrieving sociotechnical change from technological determinism, in M.R. Smith and L. Marx (eds.), Does technology drive history? The dilemma of technological determinism, Cambridge, MA: MIT Press, pp. 115-141.

Müller, S. D., Mathiassen, L., Saunders, C., \& Kræmmergaard, P. (2017). Political Manoeuvring During Business Process Transformation: A Pluralist Approach. Journal of the Association for Information Systems, 18(3), 3.

Müller, S. D., Mathiassen, L., \& Saunders, C. (2020). Pluralist Theory Building: A Methodology for Generalizing from Data to Theory. Journal of the Association for Information Systems, 21(1), 9.

Nelson, R. R., \& Winter, S. (1982). An Evolutionary Theory of Economic Change. Cambridge, MA: Belknap Press/Harvard University Press.

Noble, D. F. (1978). Social Choice in Machine Design: The Case of Automatically Controlled Machine Tools, and a Challenge for Labor. Politics \& Society, 8(3-4), 313-347.

Orlikowski, W. J., \& Gash, D. C. (1994). Technological frames: making sense of information technology in organizations. ACM Transactions on Information Systems (TOIS), 12(2), 174207.

Orlikowski, W. J. (1996). Improvising organizational transformation over time: A situated change perspective. Information Systems Research, 7(1), 63-92.

Orlikowski, W. J. (2000). Using technology and constituting structures: A practice lens for studying technology in organizations. Organization Science, 11(4), 404-428.

Orlikowski, W. J., \& Iacono, C. S. (2001). Research commentary: Desperately seeking the "IT" in IT research-A call to theorizing the IT artifact. Information Systems Research, 12(2), 121-134.

Orlikowski, W. J. (2002). Knowing in practice: Enacting a collective capability in distributed organizing. Organization Science, 13(3), 249-273.

Orlikowski, W. J. (2007). Sociomaterial practices: Exploring technology at work. Organization Studies, 28(9), 1435-1448.

Orlikowski, W. J., \& Scott, S. V. (2008). Sociomateriality: Challenging the Separation of Technology, Work and Organization. The Academy of Management Annals, 2(1), 433-474.

Parmigiani, A., \& Howard-Grenville, J. (2011). Routines revisited: Exploring the capabilities and practice perspectives. Academy of Management Annals, 5(1), 413-453.

Pentland, B. T., \& Feldman, M. S. (2005). Organizational routines as a unit of analysis. Industrial and Corporate Change, 14(5), 793-815.

Pentland, B. T., \& Feldman, M. S. (2008). Designing routines: On the folly of designing artifacts, while hoping for patterns of action. Information and Organization, 18(4), 235-250. 
Pickering, A. (1995). The Mangle of Practice: Time, Agency, and Science. Chicago: University of Chicago Press.

Poole, M. S., \& DeSanctis, G. (1990). Understanding the Use of Group Decision Support Systems: The Theory of Adaptive Structuration, in J. Fulk and C. Steinfield (eds.), Organizations and communication technology, Sage Publications, pp. 173-193.

Putnam, L. L. (2015). Unpacking the dialectic: Alternative views on the discourse-materiality relationship. Journal of Management Studies, 52(5), 706-716.

Rerup, C., \& Feldman, M. S. (2011). Routines as a source of change in organizational schemata: The role of trial-and-error learning. Academy of Management Journal, 54(3), 577-610.

Rice, R. E., \& Aydin, C. (1991). Attitudes toward new organizational technology: Network proximity as a mechanism for social information processing. Administrative Science Quarterly, 219-244.

Romanelli, E., \& Tushman, M.L. (1994). Organizational transformation as punctuated equilibrium: An empirical test. Academy of Management Journal, 37(5), 1141-1166.

Sabherwal, R., Hirschheim, R., \& Goles, T. (2001). The dynamics of alignment: Insights from a punctuated equilibrium model. Organization Science, 12(2), 179-197.

Schultze, U., \& Orlikowski, W. J. (2004). A practice perspective on technology-mediated network relations: The use of Internet-based self-serve technologies. Information Systems Research, 15(1), 87-106.

Seidel, S., Recker, J., \& Vom Brocke, J. (2013). Sensemaking and sustainable practicing: functional affordances of information systems in green transformations. MIS Quarterly, 27(4), 1275-1299.

Vaast, E., \& Walsham, G. (2005). Representations and Actions: the Transformation of Work Practices with IT Use. Information and Organization, 15(1), 65-89.

Verhulst, M., \& Rutkowski, A. F. (2017). Catch me if you can: Technological constraints/affordances and mindfulness during collaborative police emergency response. In Proceedings of the 50th Hawaii International Conference on System Sciences.

Vial, G. (2019). Understanding digital transformation: A review and a research agenda. The Journal of Strategic Information Systems, 28(2), 118-144.

Vishwanath, A. (2006). The effect of the number of opinion seekers and leaders on technology attitudes and choices. Human Communication Research, 32(3), 322-350.

Watson, R. T., DeSanctis, G., \& Poole, M. S. (1988). Using a GDSS to facilitate group consensus: Some intended and unintended consequences. MIS Quarterly, 12(3), 463-478.

Weick, K.E. (1979). The Social Psychology of Organizing (2nd ed.). New York: McGraw-Hill.

Weick, K. E. (1993). Organizational redesign as improvisation, in G.P. Huber and W.H. Glick, (eds.), Organizational Change and Redesign: Ideas and Insights for Improving Performance, , 379. Oxford: Oxford University Press, pp. 346- 379.

Wessel, L., Baiyere, A., Ologeanu-Taddei, R., Cha, J., \& Jensen, T. (2020). Unpacking the difference between digital transformation and IT-enabled organizational transformation. Journal of Association of Information Systems, 22(1), 6. 
Winter, S. G. (2003). Understanding dynamic capabilities. Strategic Management Journal, 24(10), 991-995.

Zuboff, S. (1988). The Future of Work and Power. In the Age of the Smart Machine. New York: Basic Books.

Copyright: (C 2021 Taj, Kautz \& Bruno. This is an open-access article distributed under the terms of the Creative Commons Attribution-NonCommercial 3.0 Australia License, which permits non-commercial use, distribution, and reproduction in any medium, provided the original author and AJIS are credited.

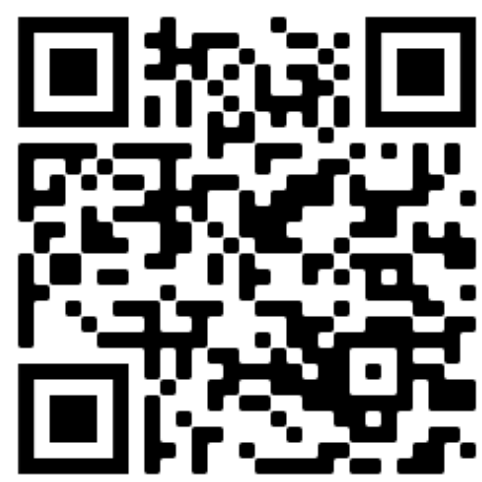

